\title{
Estimation of small ion concentration near the Earth's surface
}

\author{
Nagaraja Kamsali $^{\text {a,* }}$, S.D. Pawar ${ }^{\text {b }}$, P. Murugavel ${ }^{\text {b }}$, V. Gopalakrishnan ${ }^{\text {b }}$ \\ a Department of Physics, Bangalore University, Bangalore 560056, India \\ ${ }^{\mathrm{b}}$ Indian Institute of Tropical Meteorology, Pune 411008, India
}

\section{A R T I C L E I N F O}

\section{Article history:}

Received 27 September 2010

Received in revised form

23 July 2011

Accepted 28 July 2011

Available online 11 August 2011

\section{Keywords:}

Radon

Ionization

Aerosols

Small ion concentration

Ion-aerosol interactions

\begin{abstract}
A B S T R A C T
Atmospheric ions produced by radon gas exhalation from the Earth's surface can play a vital role in the electrification of atmosphere, especially during nights when the gases are trapped in a stable layer close to the surface. The measurements of concentration of radon and its progeny, air conductivity and aerosol size distribution made at Pune, India, have been analyzed. The concentrations of radon and its progeny show maxima during night and early morning hours, between 0500 and 0700 IST when atmosphere is more stable and mixing is low and start decreasing after sunrise and attain minima during $1000-1800 \mathrm{~h}$ when air is unstable. The diurnal variation of the ionization rate, calculated using the concentrations of radon and its progeny, follows the variations of concentrations of radon and its progeny. The ion-aerosol balance equations are solved to study the effect of aerosols on small ion concentration in the lower atmosphere. It has been found that during daytime when aerosol concentration is high, $20-30 \%$ reduction in small ion concentration can occur due to aerosols. The small ion concentration estimated using measured air conductivity is compared with small ion concentration estimated by solving ion-aerosol balance equations and both are found to be in good agreement with each other.
\end{abstract}

(c) 2011 Elsevier Ltd. All rights reserved.

\section{Introduction}

The study of atmospheric ions near the Earth's surface is the subject of a large number of scientific papers. Although extensive observations and simulations have substantially advanced, the formation and loss of the ions is not yet fully understood, (Mohnen, 1977; Perkins and Eisele, 1984; Luts, 1998). It has been now recognized that atmospheric ions not only play important role in determining the electrical state of atmosphere but also can affect the aerosol and cloud properties and ultimately on climate (Harrison, 2000; Yu and Turco, 2001; Carslaw et al., 2002; Harrison and Carslaw, 2003). Harrison and Carslaw (2003) have discussed in detail the influence of atmospheric charged particles on aerosols and cloud microphysical processes, and the importance of ionization rate by considering the variations in global cloudiness and weather systems. Close to the ground surface, in continental regions, the radioactive radiation from ground and galactic cosmic rays are major sources of ionization (Shamos and Liboff, 1966; Petrov et al., 2009). The rocks and soil in the solid Earth contain radioactive elements such as uranium, thorium, etc. in the form of minerals like monazite, their concentrations varying from region to region. Radiation from radioactive gases

\footnotetext{
* Corresponding author. Tel.: +91 802296 1478; fax: +91 8023219295.

E-mail address: kamsalinagaraj@bub.ernet.in (N. Kamsali).
}

exhaled from the ground surface and their daughter's cause ionization in the Earth's atmosphere (Wilkening, 1990). Radon is one of the relatively longer-lived gases. The principal decay modes and half-lives of ${ }^{222} \mathrm{Rn}$ and its short-lived progeny in order are ${ }^{222} \mathrm{Rn}-\alpha$, 3.82 days; ${ }^{218} \mathrm{Po}-\alpha, 3.05 \mathrm{~m} ;{ }^{214} \mathrm{~Pb}-\beta, 26.8 \mathrm{~m} ;{ }^{214} \mathrm{Bi}-\beta$, $19.7 \mathrm{~m}$ and ${ }^{214} \mathrm{Po}-\alpha, 2 \times 10^{-4}$ s. The radiations such as $\alpha, \beta$ and $\gamma$ during the decay of radon and its progeny cause ionization, and hence these are important in the study of atmospheric electricity. The amount of radon that escapes depends on the amount of ${ }^{226} \mathrm{Ra}$ in the ground, the type of ground cover and porosity, dampness and temperature of the soil. It is obvious that the radiation directly from ground will vary greatly depending on the geographical variations in ground radioactivity. Further, the ionization due to radioactive gases in the air is even more variable and depends not only on the amount exhaled from ground but also on atmospheric dispersion. Direct measurement of ionization due to radioactive gases in the atmosphere is difficult. Estimation of ionization rate is therefore based on measurements of radioactive products in air. The radioactivity of air is controlled by the local meteorological, geological and dynamical conditions, and gives a picture of the rate of the accumulation of the escape from the lower atmosphere of substance released by the soil. Hence, the concentration of small ions is known to vary with altitude, latitude, solar activity and several other factors like atmospheric aerosol concentration, meteorological parameters and local conditions. 
Air molecules attach themselves to primary ion-pairs (singlecharged positive ion and free electron) by ionization processes to form 'cluster ions' known as small ions. Consequently, large and intermediate ions are formed by the attachment of small ions to uncharged aerosol particles. The main characteristic of air ion is electrical mobility, which is a function of its mass and size. The mobility of an ion is defined as the velocity acquired by the ion in a unit electric field at a temperature and pressure of $0{ }^{\circ} \mathrm{C}$ and $760 \mathrm{~mm}$ of $\mathrm{Hg}$, respectively. The mobility of ion depends upon the ionic properties such as size, mass and charge as well as the physical properties such as pressure, humidity, etc. of the atmosphere in which it moves and varies in the wide range between $10^{-4} \mathrm{~m}^{2} \mathrm{~V}^{-1} \mathrm{~s}^{-1}$ for small ions and $10^{-7}-10^{-8} \mathrm{~m}^{2} \mathrm{~V}^{-1} \mathrm{~s}$ for large ions. Since the mobility of small ions is at least four orders of magnitude more than that of large ions, small ions are considered as the main contributors to the local electrical conductivity of atmosphere (Dhanorkar and Kamra, 1997). The concentration of small ions is one of the most fundamental electrical properties in atmosphere. Ion concentration, ionic mobility, electrical conductivity, etc. are important parameters for understanding the electrical nature of atmosphere.

The electrical nature of air in an aerosol-free atmosphere is mainly due to small ions. In the aerosol-free atmosphere, ion-ion recombination causes a decrease in small ion concentration. However, in polluted regions, attachment of small ions to aerosol particles also plays an important role in the decrease of small ion concentration. The small ions formed due to radioactivity of the Earth's surface are destroyed by recombination of ions of opposite signs, by combination with uncharged or oppositely charged aerosol particles. Even small changes in the size distribution of aerosols due to changes in meteorological conditions or to changes in the production rate of aerosol particles may largely affect the electrical state of atmosphere (Dhanorkar and Kamra, 1993). Tammet (1988) has surveyed the studies of small air ions and their interactions with the air molecules and aerosols in the surface layer and points out that the application of atmospheric electricity methods in monitoring the natural environment might play a central role in future studies. However, in a polluted atmosphere these ions are soon attached to the aerosol particles and form the intermediate and large ions. Since the mobility of small ions is at least four orders of magnitude more than that of large ions, small ions are considered to be the main contributors to the local electrical conductivity of atmosphere (Dhanorkar and Kamra, 1997).

The conductivity of air is related to the concentration of small ions by the equation, $\sigma=N e b$, where $\sigma$ is air conductivity, $e$ is electronic charge and $b$ is an average mobility of small ions. Small ions determine not only the conductivity of air but also influence other atmospheric electricity parameters like air-earth current, atmospheric electric field and space charge (Ogawa, 1985; Hoppel et al., 1986; Rycroft et al., 2000).

Thus, the aerosol loading reduces the concentration of ions in the atmosphere by either converting the highly mobile small ions into less mobile aerosol ions through ion-aerosol attachment and/or neutralizing the small ions through the aerosol-ion small ion recombination. Another process that makes the ion-aerosol attachment rate faster is the charged aerosol-aerosol recombination. Several theoretical studies on ion-aerosol interaction for higher altitudes are available (Datta et al., 1987; Prasad et al., 1991; Srinivas and Prasad, 1996). Most of the studies have considered the loss of small ions as solely due to (a) ion-ion recombination and (b) ion attachment to aerosols. The other two types of loss of small ions arise from the recombination of molecular ions with oppositely charged aerosol and charged aerosol-aerosol recombination, and they further deplete the small ions. Obviously, addition of these two terms results in more realistic values (Srinivas et al., 2001). The equilibrium density of small ions is governed by the equations of continuity for the production and loss of these ions, where the gain and loss due to transport are negligible. The attachment of small ions to neutral aerosols produces charged aerosols referred to as 'large ions', which are less mobile than the smaller molecular ions. The subsequent recombination of charged aerosols with ions as well as oppositely charged aerosols would result in the depletion of small ion concentration more rapidly than in the absence of aerosols. The production and the loss of these ions is governed by a set of equations involving different attachment and recombination processes. These equations are based on the assumption that there are equal numbers of positive and negative small ions in atmosphere and aerosols are symmetrically charged. However, close to the surface of Earth, because of the electrode effect there exists an imbalance between positive and negative small ions. Further, the assumption of symmetric charging of aerosols is not valid in the urban areas where aerosol concentration is high.

Here, we have studied the ion-aerosol recombination processes in the atmosphere using measurements of radon concentration, aerosol size distribution, air conductivity and meteorological parameters made at a tropical station Pune (18.32N, 73.5E), India. The aim of this work is to verify the ion-aerosol balance equations. The general assumption in ion-balance is that numbers of positive and negative small ions are equal and are charged symmetrically. However, close to Earth's surface, because of the electrode layer effect, there exists an imbalance between positive and negative small ions, and also the assumption of symmetric charging of aerosols is not valid where aerosol concentration is high. Here an effort is made to find out under what conditions the ion concentration derived by ion-balance equation matches/mismatches with observed ion concentration.

\section{Experiment and methodology}

The measurements of radon concentration, aerosol size distribution and air conductivity were made at the atmospheric electricity observatory in the campus of Indian Institute of Tropical Meteorology, Pune, India, for 6 days during 21-27 April 1998. The observatory is located on the outskirts of the city and relatively free from air pollution produced by vehicular traffic and human activities. The details of experimental setup for the measurement of radon and its progeny to obtain ion production rate are given in Prasad et al. (2005) and Nagaraja et al. (2009) and here it is briefly discussed for the continuity of presentation. Simultaneous measurements of temperature, relative humidity, pressure and wind speed have been made. Small ion concentration is estimated from the ion-aerosol balance equations and is compared with the simultaneously measured experimental conductivity. Also, the percent decrease of small ion concentration in the presence of aerosols is estimated.

\subsection{Radon concentration in air:}

Concentration of radon in air is measured using the low level radon detection system (Nagaraja et al., 2003a). The procedure briefly consists of sampling the air in a collection chamber and exposing a circular metallic disk to the radon inside the collection chamber. A delay of at least $10 \mathrm{~min}$ is normally allowed for any thoron that may be present in the chamber to decay completely. The positively charged polonium atoms created in the chamber get collected on the metallic plate maintained at an optimum negative potential, which should be sufficient to force all the polonium atoms onto the plate. The collection is carried out for an optimized period and thereafter the charged plate is removed 
from the chamber and alpha-counted. Then the concentration of radon (in $\mathrm{Bq} \mathrm{m}^{-3}$ ) is estimated (Nagaraja et al., 2003b).

\subsection{Radon progeny concentration in air}

The radon concentration in air is measured using an air flow meter. Air is drawn through a glass fiber filter paper by means of a suction pump at a known flow rate. The radon progeny in air sample is retained on the filter paper. The filter paper is then alpha-counted at any specific delay time. Activities (in $\mathrm{Bq} \mathrm{m}^{-3}$ ) of progenies, i.e. polonium ( $\mathrm{RaA})$, lead ( $\mathrm{RaB})$ and bismuth ( $\mathrm{RaC}$ '), are calculated (Nagaraja et al., 2003b).

\subsection{Ion-pair production rate}

The ion-pair production rate (ion pair $\mathrm{cm}^{-3} \mathrm{~s}^{-1}$ ) due to radon and its progeny is calculated using the expression

$q=\frac{5.49 C_{\mathrm{Rn}}+6.00 C_{\mathrm{RaA}}+0.85 C_{\mathrm{RaB}}+7.69 C_{\mathrm{RaC}}}{32}$

where $C_{\mathrm{Rn}}$ is the concentration $\left(\mathrm{Bq} \mathrm{m}^{-3}\right)$ of radon. $C_{\mathrm{RaA}}, C_{\mathrm{RaB}}$ and $C_{\mathrm{RaC}}$ are the concentrations $\left(\mathrm{Bq} \mathrm{m}^{-3}\right)$ of radon progenies.

Here, energy released by the decay of radon and its progenies are in $\mathrm{MeV}$ and the energy required to produce one ion pair is $32 \mathrm{eV}$.

\subsection{Aerosol concentration}

The aerosol measurements are made with a TSI 3030 Electrical Aerosol Analyzer (EAA). The EAA is capable of performing rapid in situ size distributions on aerosols from 0.013 to $1 \mu \mathrm{m}$ diameter. The instrument is based on the diffusion charging mobility analysis principle. The instrument samples ambient air at the rate of $50 \mathrm{lpm}$ (litres per minute), of which $4 \mathrm{lpm}$ is needed for the aerosol sampling measurements; the remainder is clean air needed by the mobility analyzer $(45 \mathrm{lpm})$ and the diffusion charger $(1 \mathrm{lpm})$. Samples are first exposed to a $\mathrm{Kr}^{85}$ radioactive neutralizer and then passed through a mobility analyzer that contains concentric cylindrical electrodes and a central collector rod. A brief description of EAA is given in Liu and Pui (1975). A computer is interfaced with an analyzer to measure the size distribution.

\subsection{Air conductivity}

Both polarities of conductivity $\left(\sigma_{+}\right.$and $\sigma_{-}$) are measured with a Gerdien apparatus placed at $1 \mathrm{~m}$ height. The design and working of the instrument is described in detail by Dhanorkar and Kamra (1992). It consists of two identical cylindrical condensers connected with a U-shaped tube. The air is drawn through the condensers with a common fan fixed in the U-shaped tube. The sensor rods inside the cylinders are insulated from the outer cylinder by Teflon bushes. The critical mobility of the apparatus is adjusted at $3.6 \times 10^{-4} \mathrm{~m}^{2} \mathrm{~V}^{-1} \mathrm{~s}^{-1}$. The critical mobility is defined as the mobility for which all the ions of equal or greater than this mobility are collected by the sensor. The signals from both the condensers are amplified with an electrometer, AD-311K. AD$311 \mathrm{~K}$ is a varactor bridge operational amplifier with very low-bias current of the order of $10^{-14} \mathrm{~A}$, low voltage drift $10 \mu \mathrm{V} /{ }^{\circ} \mathrm{C}$ and very high input impedance of the order of $10^{14} \Omega$.

\section{Ion-aerosol balance equation}

The ion concentration in the atmosphere is one of the important parameters for understanding the electrical nature of the
Earth's atmosphere. This parameter is sensitive to the presence of aerosols. Thus, the aerosol loading has a bearing on the concentration of the atmosphere. The aerosols reduce the ion concentration by (i) converting the highly mobile small ions to less mobile aerosol ions through ion-aerosol attachment and (ii) neutralizing the small ions through the aerosol-ion-small ion recombination. Another process that makes the ion-aerosol attachment rate faster is the charged aerosol-aerosol recombination. We take into consideration ion-aerosol interactions to validate computed and the experimental values of small ion concentration.

The scheme involves primary ion-pair production rate due to surface radioactivity and cosmic rays, the small ion densities $\left(N_{ \pm}\right)$and the aerosol number density. For the model prediction of equilibrium ion density, it is necessary to use all the four loss processes of ions involved. The various recombination coefficients that enter into the model are

(a) $\alpha_{i}$ due to the loss of oppositely charged small ions

(b) $\alpha_{\mathrm{a}}$ due to oppositely charged aerosol ions

(c) $\alpha_{\mathrm{s}}$ is between small ions and aerosol ions

(d) $\beta$ due to attachment of small ions of similar polarities with aerosols.

The temperature, pressure, relative humidity, ionization rate and aerosol number density along with the different attachment/ recombination coefficients are used to estimate the small ion concentration. However, the estimation does not make any distinction between positive and negative ion concentrations. In the present study, the detailed reaction paths for the formation of individual cluster ions are not considered. The total number densities of positive and negative ions are assumed to be equal from the charge neutrality criterion. The equilibrium ion densities are computed from the equations of continuity, where the effect of transport is neglected. These equations include the aforementioned four types of loss processes. The attachment coefficients, $\beta$ for positive and negative ions with neutral aerosols and recombination coefficient $\alpha$ for positive and negative ions with oppositely charged aerosols, are assumed to be equal. The equations of continuity (i) for small ions in the absence of aerosols and in the presence of aerosols and (ii) the charged aerosols are given by

$\frac{\mathrm{d} N_{0}}{\mathrm{~d} t}=q-\alpha_{\mathrm{i}} N_{0}^{2}$

$\frac{\mathrm{d} N_{ \pm}}{\mathrm{d} t}=q-\alpha_{\mathrm{i}} N_{ \pm}^{2}-\beta Z N_{ \pm}-\alpha_{\mathrm{s}} A_{ \pm} N_{\mp}$

$\frac{\mathrm{d} A_{ \pm}}{\mathrm{d} t}=\beta Z N_{ \pm}-\alpha_{\mathrm{s}} A_{ \pm} N_{\mp}-\alpha_{\mathrm{a}} A_{ \pm}^{2}$

where $q$ is the ion production rate due to radioactivity and cosmic rays; $N_{0}$ is positive/negative ion density in the absence of aerosols; $N_{ \pm}$and $N_{\mp}$ are positive/negative ion densities in the presence of aerosols; $A_{ \pm}$is positively/negatively charged aerosol density; $Z$ is neutral aerosol number density; $\beta$ is the aerosol-ion attachment coefficient; $\alpha_{i}$ is the ion-ion recombination coefficient; $\alpha_{\mathrm{s}}$ is the charged aerosol-ion recombination coefficient and $\alpha_{\mathrm{a}}$ is the charged aerosol-aerosol recombination coefficient.

Under steady state conditions Eqs.(2), (3) and (4) reduce, respectively, to

$q-\alpha_{\mathrm{i}} N_{0}^{2}=0 \Rightarrow N_{0}=\left(\frac{q}{\alpha_{\mathrm{i}}}\right)^{1 / 2}$

$q-\alpha_{\mathrm{i}} N_{ \pm}^{2}-\beta Z N_{ \pm}-\alpha_{\mathrm{s}} A_{ \pm} N_{\mp}=0$

$\beta Z N_{ \pm}-\alpha_{\mathrm{s}} A_{ \pm} N_{\mp}-\alpha_{\mathrm{a}} A_{ \pm}^{2}=0$ 
Solving Eqs.(5)-(7) for $N_{ \pm}$with $A_{ \pm}=N_{0}-N_{ \pm}$we get

$N_{ \pm}=\frac{\left(\alpha_{\mathrm{a}} N_{0}+\beta Z\right) \pm \sqrt{\left(\alpha_{\mathrm{a}} N_{0}+\beta Z\right)^{2}-\left(\alpha_{\mathrm{a}}-\alpha_{\mathrm{i}}\right)\left(q+\alpha_{\mathrm{a}} N_{0}^{2}\right)}}{\left(\alpha_{\mathrm{a}}-\alpha_{\mathrm{i}}\right)}$

Solving Eqs. (6) and (7) simultaneously, one can get

$\beta Z=\left(\frac{q-\alpha_{\mathrm{i}} N_{ \pm}^{2}+\alpha_{\mathrm{a}} A_{ \pm}^{2}}{2 N_{ \pm}}\right)$

$\alpha_{s}=\left(\frac{q-\alpha_{\mathrm{i}} N_{ \pm}^{2}+\alpha_{\mathrm{a}} A_{ \pm}^{2}}{2 A_{ \pm} N_{\mp}}\right)$

The ion depletion $\Delta N$, i.e. loss of molecular ions in the presence of aerosols, is given by $\Delta N=N_{0}-N_{ \pm}$. Further, this ion depletion is equal to the charged aerosol concentration, $A_{ \pm}$. Hence, the fractional depletion, $\eta$ of small ions is used and computed as follows:

$\eta=\left(\frac{\Delta N}{N_{0}}\right)=\left(\frac{A_{ \pm}}{N_{0}}\right)$

Using Eqs. (11) and (5), we can write Eqs.(9) and (10), respectively, as

$\beta Z=\left(\frac{N_{0} \eta\left[\alpha_{\mathrm{i}}(2-\eta)+\alpha_{\mathrm{a}} \eta\right]}{2(1-\eta)}\right)$

$\alpha_{\mathrm{s}}=\left(\frac{\alpha_{\mathrm{i}}(2-\eta)-\alpha_{\mathrm{a}} \eta}{2(1-\eta)}\right)$

Estimation of small ion concentration of the atmosphere requires knowledge of recombination coefficients $\alpha_{\mathrm{i}}, \alpha_{\mathrm{a}}$ and $\alpha_{\mathrm{s}}$. The value of $\alpha_{\mathrm{i}}$ is estimated from the parametric formula of Smith and Adams (1982) using neutral density of Cole and Kantor (1978). From theoretical considerations, Hoppel (1985) has shown that, for singly charged aerosols, the relative magnitudes of $\alpha_{\mathrm{a}}$ and $\alpha_{\mathrm{s}}$ are such that $\alpha_{a} \leq \alpha_{s} \leq \alpha_{i}$. Initially, with a suitable assumed value of $\alpha_{a}$ the value of $\eta$ is computed from Eq. (11); then the value of $\alpha_{s}$ is computed using Eq. (13). It is noted that, in this step, $\alpha_{s}$ becomes negative if the assumed value of $\alpha_{\mathrm{a}}$ is unrealistically large. In the present computations $\alpha_{\mathrm{a}}=10^{-13} \mathrm{~m}^{3} \mathrm{~s}^{-1}$ is found to be suitable. In the presence of aerosols and depending on the magnitude of $\alpha_{\mathrm{i}}, \alpha_{\mathrm{s}}$ and $\beta \mathrm{Z}$, the realistic values of $\Delta N$ are obtained that lie between zero and $N_{0}$ and satisfy the condition $0<N_{+}<N_{0}$. The values of $\beta \mathrm{Z}$ and $\alpha_{\mathrm{s}}$ are obtained by solving Eqs. (9) and (12) simultaneously for $\beta Z$ and Eqs. (10) and (13) for $\alpha_{s}$ through an iterative procedure until the difference between the values gets minimized. These values are substituted in Eq. (8) to obtain $N_{ \pm}$. By knowing the experimental values of $q, Z, T, P$ and different attachment and recombination coefficients computed from the ion-aerosol balance equations, it is possible to estimate the values of $N_{0}$ and $N_{ \pm}$.

\section{Results and discussion}

The variations of activity of radon and its progeny near the Earth's surface obtained on April 21, 1998 are shown in Fig. 1(a). As shown in this figure, concentrations of radon and its progeny are high during nighttime compared to daytime. The concentrations start increasing during night and attain maximum in early morning hours, between 0500 and 0700 IST, when atmosphere is the most stable and mixing is low. The concentration decreases after sunrise and remains almost steady during 1000-1800 h, when air is unstable. The radioactive emanations from the ground are trapped below inversions, and their accumulation causes an increase in ionization in the lower stable atmosphere during nighttime (Hoppel et al., 1986). An experimental observation of Porstendorfer et al. (1991) confirms such accumulation of radon and its short-lived decay products close to the Earth's surface

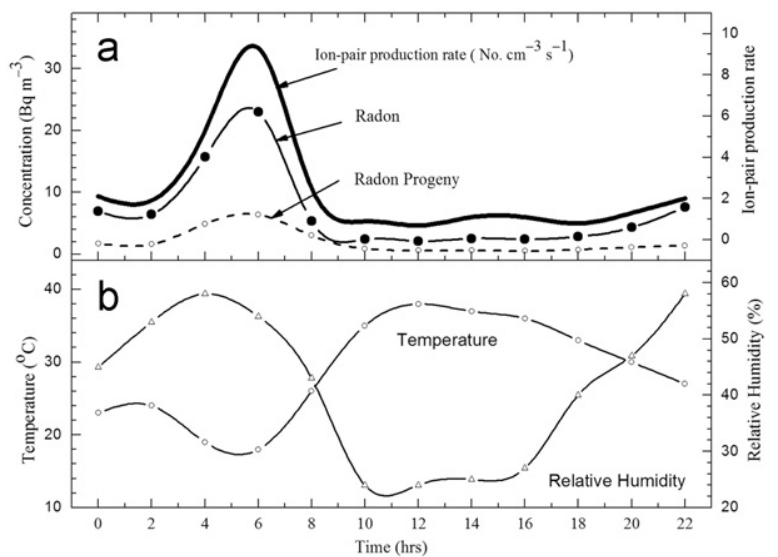

Fig. 1. Diurnal variation of (a) radon, its progeny and ionization rate and (b) temperature and relative humidity observed on April 21, 1998

during nighttime. The radon concentration varies over a magnitude of 11 from its maximum to minimum with a median of $6.8 \mathrm{~Bq} \mathrm{~m}{ }^{-3}$, showing a significant diurnal variation, whereas progeny has a magnitude of 13 with a median of $2.0 \mathrm{~Bq} \mathrm{~m}^{-3}$. The variations of temperature and relative humidity for the same day are shown in Fig. 1(b). The variations in radon and its progeny show inverse relation with temperature, which also support the idea that stability of atmosphere plays an important role in these concentrations. Increase in temperature causes increased vertical mixing, which leads to turbulence and raise of radioactive aerosols to the higher altitudes and subsequent reduction in concentration of radon at the ground level. The radon gas exhaled from the Earth's surface decays to its progenies and most of them are positively charged. These ions attach to aerosol particles and lead to reduction in progeny concentration near the surface by the onset of convection after sunrise (Raghavayya, 1998; Nagaraja et al., 2003b). Measurements of air conductivity and space charge at this place by Pawar and Kamra (2000) and Kulkarni et al. (2010) also show high values during night compared to day. They have attributed such high value of space charge density and conductivity to the increased radioactive gas concentration near the Earth surface due to stable atmosphere during that time. Using the values of radon and its progeny and other meteorological parameters, the values of small ion production rate $q$ is estimated using Eq. (1). The diurnal variation of $q$ also is plotted in Fig. 1(a). Near the surface of Earth, the ionization due to radioactive gases and their progenies is predominantly due to the alpha particles. The radon exhaled from the surface causes ionization of atmosphere (Israel, 1970) that exhibits the diurnal variation as that of concentration of radon and its progeny with a maximum in the early morning hours and a minimum in the afternoon as depicted in Fig. 1(a). The ion-pair production rate varies from 0.7 to 9.3 ion pair $\mathrm{cm}^{-3} \mathrm{~s}^{-1}$ with a mean of 2.5 ionpairs $\mathrm{cm}^{-3} \mathrm{~s}^{-1}$. It shows a variability of 13 times the magnitude from its maximum to minimum. Accumulation of radioactive emanations will increase through night until morning, hence leading to the enhancement of ionization in atmosphere. Fig. 2.

The diurnal variation of concentration of aerosols in the size range of 13-750 nm diameter observed on 21 April 1998 is shown in Fig. 3. The concentration attains minimum during the early morning around $0600 \mathrm{hIST}$ and an increasing trend towards noon-hours. The size distributions are generally bimodal with their maxima at 75 and $23 \mathrm{~nm}$ during night. In the early morning hours there is a slight shift in maxima in the accumulation mode towards the higher size. During daytime, particularly in the afternoon, the shift in maxima in the accumulation mode to a higher diameter of $133 \mathrm{~nm}$ is distinct and the maxima in the 


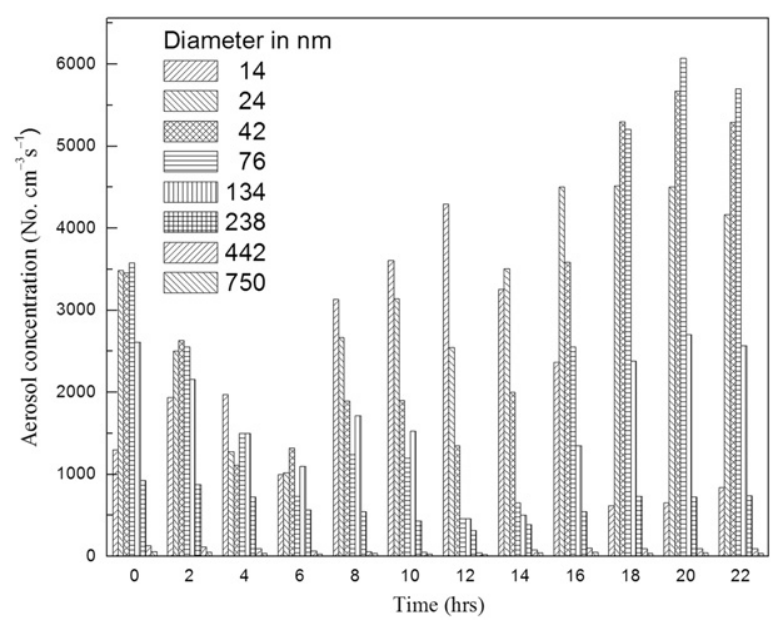

Fig. 2. Diurnal variation of concentrations of aerosols of different radii measured on 21 April 1998.

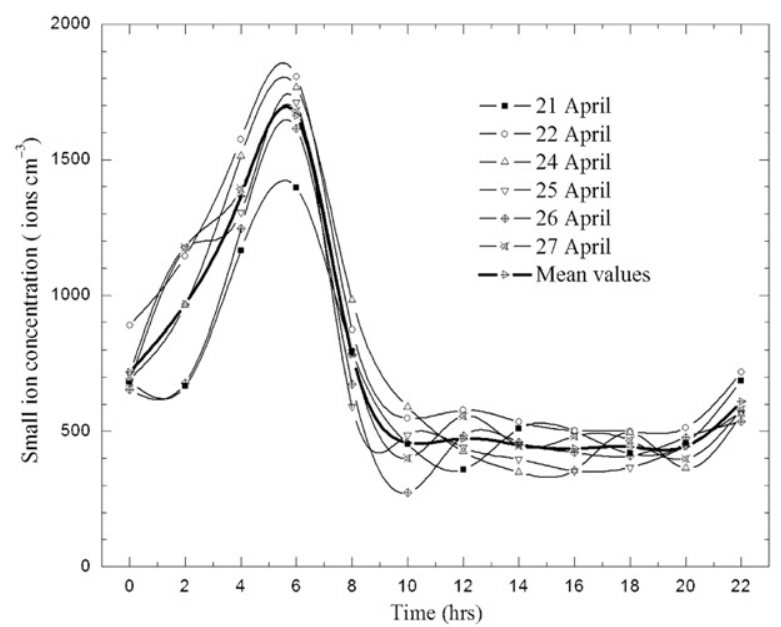

Fig. 3. Diurnal variation of small ion concentration estimated from ion-aerosol balance equations. Thick line is the mean values obtained for the period 21-27 April 1998, and thin lines refer to the variations on individual days.

nucleation mode seem to shift to smaller diameter. The size distribution curves during daytime are mostly open ended at the small particle side due to the increase in the concentration of small particles (Murugavel and Kamra, 1999).

The diurnal variation of estimated small ion concentration is shown in Fig. 3 for a period of 1 week along with its mean values. Relatively a large day-to-day difference in the concentrations of ions that may arise from the difference in the accumulations of radioactive emanations and aerosol particles due to varying degrees of the lower atmospheric stability and/or due to varying intensities of advection. It is observed that the concentration shows maxima in the early morning around $0600 \mathrm{~h}$ IST, decreases after sunrise and attains minimum in the afternoon. Radioactive emanations from ground are trapped below inversions, and their accumulations cause an increase in ionization and consequently increase in concentration in the lower atmosphere during nighttime (Hoppel et al., 1986). Under unstable conditions during daytime, the radioactive gas gets dispersed to higher altitudes and hence ionization rates close to the Earth's surface reduce. Dispersion of radioactive aerosols to higher altitudes leads to decrease in their concentration near the Earth's surface and hence reduction in ionization from the decay of radon progenies. During the low wind and temperature inversion conditions at nighttime, the radioactive gases accumulate close to the Earth's surface and thus cause higher ionization rates. The increase in ionization rate is mainly because of radon and its progeny in atmosphere. Radon, being a gas, accumulates more near the surface during nighttime and in the early morning hours due to less turbulence. As the day advances the temperature increases and hence the turbulence increases, thereby reducing ionization in the afternoon (Nagaraja et al., 2006). The concentration varies between 436 and 1663 ion $\mathrm{cm}^{-3}$ with a mean of 734 ion $\mathrm{cm}^{-3}$.

During nighttime, the atmosphere is relatively calm with low winds and little convective motion and hence the radon exhaled from the soil accumulates near the ground leads to increased ionization, and an increase in the ion concentration. After sunrise, due to onset of convection resulting from the increase in atmospheric temperature and increased anthropogenic activity, aerosols are pushed into atmosphere. This causes conversion of small ions into large ions through attachment, and may increase the destruction of small ions through recombination with large ions of opposite polarity. The onset of convection also removes radon from near the ground to higher altitude regions. These factors contribute to the observed reduction in small ion concentration in afternoon (Petrov et al., 1999). In the evening, with decreasing ground temperatures and also the anthropogenic activity, the aerosols that had been pushed to higher altitudes begin to settle down, and a greater fraction of small ions is lost through attachment and leads to the enhancement of concentration after sunset. Finally, at nightfall, the aerosols settle down, and the concentration recovers its normal nighttime high values (Dhanorkar and Kamra, 1999).

Since the major contribution to ionization at the surface comes from surface radioactivity and radon emanating from the soil, one would expect the diurnal variation pattern of small ion concentration to reflect that of the radon concentration near the surface. Radon and its short-lived daughters are understood to show a diurnal variation in concentration with a maximum early in the morning and a minimum in afternoon (Nagaraja et al., 2003a). This is ascribed to the variations in the vertical mixing of air near the surface, which is controlled by atmospheric stability. As convection builds up with solar heating of the ground the radioactive gases are also transported upward, where they add to the ambient ionization. This leads to a reduction in the concentration of these gases, and consequently of ionization, near the surface (Nagaraja et al., 2003b). Therefore one should expect higher ion concentration during the period of atmospheric stability, with the values decreasing with the onset of turbulence. The fluctuations in Fig. (3) are due to the similar variations in $q$, which in turn is affected by the variations in meteorological parameters such as temperature, relative humidity, wind speed, etc. The study has reproduced well this trend of the diurnal variation in small ion concentration.

The estimated small ion concentration shows a positive correlation with ionization rate due to surface radioactivity near the Earth's surface. There is a correlation of $98.4 \%$ and suggests that the theoretical approach is best fitted and the correlation obtained indicates the correctness of ion-aerosol interaction considerations. It is to be noted that this is the first of its kind for the estimation of small ion concentration of the atmosphere near the surface of the Earth.

Measurements by Cobb and Wells (1970), Misaki and Takeuti (1970) and Deshpande and Kamra (1995) have shown the effect of aerosols on conductivity and hence on small ion concentration over marine environment. Jonassen and Wilkening (1965), Wilkening (1985), Israelsson et al. (1994) and Dhanorkar and Kamra (1997) have established a similar influence over continents from the measurement of conductivity. Here, we show the effect of aerosols on concentration of ion from estimation of ion using the ion-balance equation. Fig. 5 presents the concentration of ions derived from the measured conductivity values. Using 
conductivity value measured from Gerdien's condenser, the ion concentration is derived by considering mobility of small ions as $1 \times 10^{-4} \mathrm{~m}^{2} \mathrm{~V}^{-1} \mathrm{~s}^{-1}$ (Dhanorkar and Kamra, 1994; Pawar et al., 2005; Harrison and Aplin, 2007).

Fig. 4 shows the estimated concentration of ions in the absence and in the presence of aerosols using Eqs. (5) and (8), respectively. There is a fair agreement between theoretically estimated small ion concentration and experimentally derived values during day time. However, there is a considerable difference between these two during early morning hours. This difference is due to the large variability in measured conductivity. Also shown in Fig. 4 is calculated percentage decrease in small ion concentration due to the presence of aerosols. The decrease is more during noontime, when the aerosol concentration is high and less in the early morning, when aerosol concentrations are minimum. The maximum reduction in the estimated small ion concentration observed at around $2000 \mathrm{~h}$ coincides with the observed maximum concentration in aerosols. It is also seen that the existence of aerosols reduces the concentration and the percent reduction of small ion concentration is found to be minimum during early morning hours and starts increasing after sunrise and remains more or less the same in afternoon till sunset and reduces afterwards. This clearly shows that aerosols influence the small ion concentration and hence the electrical structure of atmosphere.

This conclusion is further strengthened when the diurnal variation of small ion concentration deduced from ion balance equations is compared with the ion concentrations calculated using measured atmospheric conductivity (Fig. 5(a)). The conductivity values measured on April 21, 1998 were averaged for $2 \mathrm{~h}$ and ions concentrations are calculated. The vertical lines in the figure are the standard deviation. For concentrations calculated from aerosol observations, the error bar is the standard deviation of $2 \mathrm{~h}$ averaged aerosol concentration. Though there is no one-to-one match between these, the concentration obtained from these methods, the diurnal variations show the trends agree with each other. Though the variations in concentration obtained by these two methods are in phase there is considerable difference in magnitudes, especially, in early morning hours. Pawar and Kamra (2000) have observed large gradient in space charge density during nighttime due to strong electrode effect at this location. The large deviation of ion concentrations observed in early morning hours in Fig. 5(a) may be due to imbalance of polar ions during nighttime. The small differences in concentrations obtained by these two methods during daytime can be attributed to the increased aerosol concentration during that time. It is clear from the above discussion that ion-aerosol balance equations can be considered as a good estimate to explain the interactions between ions and aerosol. However, this estimate has to be taken judiciously

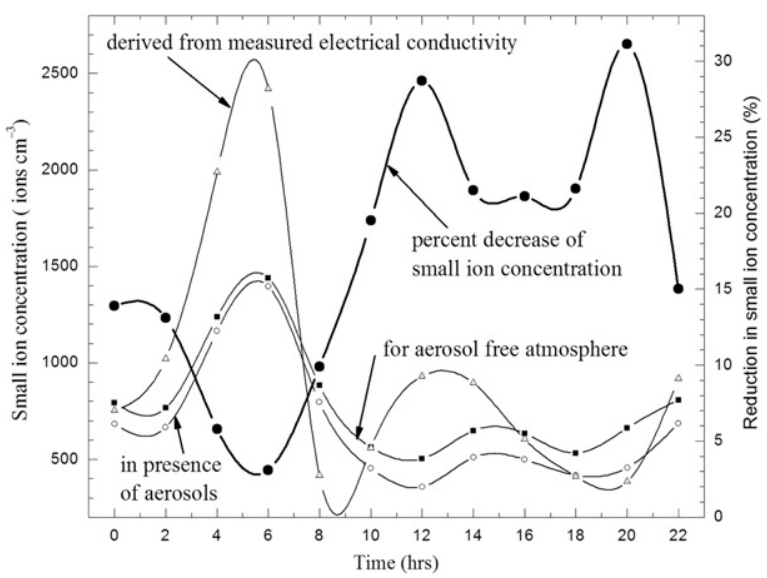

Fig. 4. Diurnal variation of small ion concentration in the presence and the absence of aerosols estimated from the ion-aerosol balance equations for April 21, 1998.
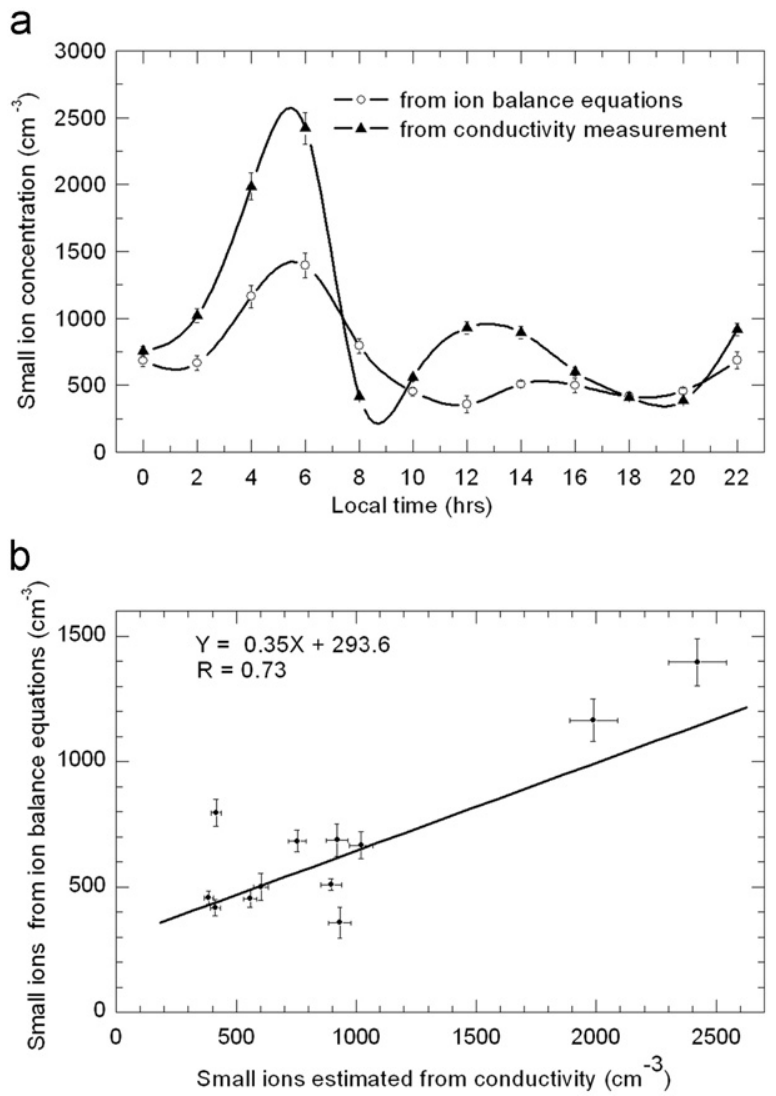

Fig. 5. (a) Diurnal variation of small ion concentration obtained from ion balance equations and concentrations derived from in situ measurements of atmospheric conductivity and (b) scattered diagram of small ion concentration estimated from ion balance equation and that derived from the experimental measurements of air conductivity for 21st April 1998. The bars are the standard deviation.

for places with high aerosol concentrations and hence strong electrode effect.

The ionization rate is a good measure of small ion concentration. Small ion concentration has positive liner regression of $98 \%$ with ion production rate obtained from radon and its progeny measurements near the Earth's surface. The estimated ion concentration from ion-aerosol balance equation matches well with the small ion concentration derived from the experimental values of electrical conductivity measured from the Gerdien setup. At Pune, India, except for 2-4 h duration around the time of sunrise, the trend matches well with each other. Our estimate also shows that except for early morning hours, the concentrations obtained by these two methods matches fairly well.

Fig. 5(b) shows the scattered plot of small ion concentration estimated from ion balance equation and that derived from the experimental measurements of air conductivity with errors bars for 21st April, 1998. The variations are within error limits except for a few points. The deviation may be due to large change in aerosol concentration. The variation shows linear dependence and has the relation $Y=0.35 X+293.6$. As seen from this plot, fair correlation exists between the concentrations obtained by these two methods. A good positive correlation of $73 \%$ between measured and estimated concentration of small ion suggests that the variations of ion concentration by both these methods are in good agreement.

\section{Summary}

The simultaneous measurements of the concentration of radon and its progeny, aerosols, ionization rate made at a height of $1 \mathrm{~m}$ 
above the surface of the Earth at Pune, India, show definite, regular and pronounced diurnal variations, which can be explained in terms of the accumulation of radioactive gases, aerosols, etc. near the surface of the Earth. The small ions concentration of the atmosphere is mainly due to the radioactive substances in the Earth's crust and their emanation near the surface. Concentration of small ion estimated from the ion-aerosol balance equations is compared with the conductivity measured. The concentration is altered because of the existence of aerosols in atmosphere. In addition, the percent decrease of small ion concentration in the presence of aerosols is also estimated and found to be a maximum (33\%) during daytime and minimum (4\%) during early morning hours, when aerosol concentration is also minimum.

The estimated small ion concentration from ion-balance equation shows a positive correlation of $98.4 \%$ with ionization rate due to surface radioactivity near the Earth's surface, which suggests that the theoretical approach described is best fitted to estimate concentration. Further, a good correlation of $87.3 \%$ is observed between small ion concentration estimated from measured conductivity and derived from ion-balance equations. This shows that the ion-aerosol balance equations may be considered good enough to explain the production and loss processes of ions in atmosphere. However, proper care should be taken before applying these to places where aerosol concentrations are high and the resultant imbalance of polar ions causes electrode effect.

\section{Acknowledgments}

One of the authors, Dr. Nagaraja Kamsali, is thankful to Dr. A.K. Kamra, Indian Institute of Tropical Meteorology, Pune, India, for the fabrication of the Gerdien condenser and helping in taking measurements in the institute and to Prof. B.S.N. Prasad, Emeritus Professor, University of Mysore, Mysore, India, for constant encouragement in carrying out this work.

\section{References}

Carslaw, K.S., Harrison, R.G., Kirkby, J., 2002. Cosmic rays, clouds and climate. Science 298, 1732-1737.

Cobb, W.E., Wells, H.J., 1970. The electrical conductivity of oceanic air and its correlation to global atmospheric pollution. J. Atmos. Sci. 27, 814-819.

Cole, A.E., Kantor, A.J., 1978. Air Force Reference Atmospheres. Scientific Report No. AFGL-TR-78-0051, Air Force Geophysics Laboratory, Hamscp, AFB, Massachusetts 01731 , pp. $1-78$.

Datta, J., Chakravarty, S.C., Mitra, A.P., 1987. A model for the cosmic ray produced ionization in the middle atmosphere. Ind. J. Radio Space Phys 16, 257-266.

Deshpande, C.G., Kamra, A.K., 1995. Extension of atmospheric aerosols over ocean around peninsular India in the southwest monsoon season. J. Aerosol Sci. 26, 1169-1174.

Dhanorkar, S., Kamra, A.K., 1992. Relation between electrical conductivity and small ions in the presence of intermediate and large ions in the lower atmosphere. J. Geophys. Res 97, 20345-20360.

Dhanorkar, S., Kamra, A.K., 1993. Diurnal and seasonal variations of the small, intermediate, and large ion concentrations and their contributions to polar conductivity. J. Geophys. Res. 98, 14895-14908.

Dhanorkar, S., Kamra, A.K., 1994. Diurnal variations of the mobility spectrum of ions and size distribution of fine aerosols in the atmosphere. J. Geophys. Res 98, 2639-2650.

Dhanorkar, S., Kamra, A.K., 1997. Calculation of electrical conductivity from ionaerosol balance equations. J. Geophys. Res. 102, 30147-30159.

Dhanorkar, S., Kamra, A.K., 1999. Effect of coagulation on the particle charge distribution and air conductivity. In: Proceedings of the 11th International Conference on Atmospheric Electricity. Guntersville, Alabama, pp. 539-542.

Harrison, R.G., 2000. Cloud formation and the possible significance of charge for atmospheric condensation and ice nuclei. Space Sci. Rev. 94, 381-396.

Harrison, R.G., Carslaw, K.S., 2003. Ion-aerosol-cloud processes in the lower atmosphere. Rev. Geophys. 41, 1012-1037.

Harrison, R.G., Aplin, K.L., 2007. Water vapour changes and atmospheric cluster ions. Atmos. Res. 85, 199-208.

Hoppel, W.A., 1985. Ion-aerosol attachment coefficients, ion depletion, and the charge distribution on aerosols. J. Geophys. Res. 90, 5917-5923.
Hoppel, W.A., Anderson, R.V., Willet, J.C., 1986. Atmospheric electricity in the planetary boundary layer, The Earth's Electrical Environment. National Academy Press, Washington, DC, USA, pp. 149-165.

Israel, H., 1970. Atmospheric Electricity. Israel Program for Scientific Translations, Jerusalem, vol. 1; pp.1-317.

Israelsson, S., Knudsen, E., Anisimov, S.V., 1994. Vertical profiles of electrical conductivity in the lowermost part of the turbulent boundary layer over flat ground. J. Atmos. Terr. Phys 56, 1545-1550.

Jonassen, M.H., Wilkening, M.H., 1965. Conductivity and concentration of small ions in the lower atmosphere. J. Geophys. Res. 91, 11909-11910.

Kulkarni, M.N., Pawar, S.D., Murugavel, P., Gopalakrishnan, V., 2010. Diurnal variation of surface currents at tropical station. J. Atmos. Sol. Terr. Phys 72, 77-82.

Liu, B.Y.H., Pui, D.Y.H., 1975. On the performance of the electrical aerosol analyzer. J. Aerosol Sci 6, 249-264.

Luts, A., 1998. Temperature variation of the evolution of positive small air ions at constant relative humidity. J. Atmos. Sol. Terr. Phys 60, 1739-1750.

Misaki, M., Takeuti, T., 1970. The extension of air pollution from land over ocean as related in the atmospheric electrical conductivity. J Meteorol. Soc. Jpn. 48, 263-269.

Mohnen, V.A., 1977. Formation, nature and mobility of ions of atmospheric importance. In: Dolezalek, H., Reiter, R. (Eds.), Electrical Processes in Atmosphere, pp. 1-17.

Murugavel, P., Kamra, A.K., 1999. Changes in the concentration and size-distribution of the sub-micron particles associated with the sea-and land-breezes at a coastal station. Curr. Sci 76, 994-997.

Nagaraja, K., Prasad, B.S.N., Madhava, M.S., Paramesh, L., 2003a. Concentration of radon and its progeny near the surface of the earth at a continental station Pune (18 N, 74 E). Ind. J. Radio Space Phys 41, 562-569.

Nagaraja, K., Prasad, B.S.N., Madhava, M.S., Chandrashekara, M.S., Paramesh, L., Sannappa, J., Pawar, S.D., Murugavel, P., Kamra, A.K., 2003b. Radon and its short-lived progeny: variations near the ground. Radiat. Meas. 36, 413-417.

Nagaraja, K., Prasad, B.S.N., Srinivas, N., Madhava, M.S., 2006. Electrical conductivity near the Earth's surface: ion-aerosol model. J. Atmos. Sol. Terr. Phys 68, 757-768.

Nagaraja, Kamsali, Prasad, B.S.N., Datta, Jayati, 2009. Atmospheric electrical conductivity measurements and modeling for application to air pollution studies. Adv. Space Res. 44, 1067-1078.

Ogawa, Toshio, 1985. Fair-weather electricity. J. Geophys. Res. 90, 5951-5960.

Pawar, S.D., Kamra, A.K., 2000. Comparative measurements of the atmospheric electric space charge density made with the filtration and Faraday Cage techniques. Atmos. Res 54, 105-116.

Pawar, S.D., Siingh, Devendraa, Gopalakrishnan, V., Kamra, A.K., 2005. Effect of the onset of southwest monsoon on the electric conductivity over the Arabian Sea. J. Geophys. Res. 91, 11909-11910.

Perkins, M.D., Eisele, F.L., 1984. First mass spectrometric measurements of atmospheric ions at ground level. J. Geophys. Res. 89, 9649-9657.

Petrov, A.I., Petrova, G.G., Panchishkina, I.N., 1999. On factors determining the variations of the electric characteristics of a surface layer. In: Proceedings of the 11th International conference on Atmospheric Electricity, Guntersville, Alabama, pp. 547-550.

Petrov, A.I., Petrova, G.G., Panchishkina, I.N., 2009. Profiles of polar conductivities and or radon-222 concentration in the atmosphere by stable and labile stratification of surface layer. Atmos. Res 91, 206-214.

Porstendorfer, J., Butterweck, G., Reineking, A., 1991. Diurnal variation of the concentrations of radon and its short-lived daughters in the atmosphere near the ground. Atmos. Environ 25, 709-713.

Prasad, B.S.N., Nagaraja, K., Chandrashekara, M.S., Paramesh, L., Madhava, M.S., 2005. Diurnal and seasonal variations of radioactivity and electrical conductivity near the surface for a continental location Mysore, India. Atmos. Res. 76, 65-77.

Prasad, B.S.N., Srinivas, N., Chandramma, S., 1991. A simplified ion-aerosol model for balloon measurements of ion conductivity and aerosol concentration. Ind. J. Radio Space Phys 20, 304-306.

Raghavayya, M., 1998. Modification of Kusnetz method for estimation of radon progeny concentration in air. Radiat. Prot. Environ 21, 127-132.

Rycroft, M.J., Israelsson, S., Price, C., 2000. The global, atmospheric electric circuit, solar activity and climate change. J. Atmos. Sol. Terr. Phys 62, 1563-1576.

Shamos, M.H., Liboff, A.R., 1966. A new measurement of the intensity of cosmicray ionization at sea level. J. Geophys. Res. 71, 4651-4659.

Smith, D., Adams, N.G., 1982. Ionic recombination in the stratosphere. Geophys. Res. Lett. 9, 1085-1087.

Srinivas, N., Prasad, B.S.N., 1996. A detailed model study of stratospheric small ion density and conductivity. Ind. J. Radio Space Phys 25, 255-262.

Srinivas, N., Prasad, B.S.N., Nagaraja, K., 2001. An ion-aerosol model study for the stratospheric conductivity under enhanced aerosol condition. Ind. J. Radio Space Phys 30, 31-35.

Tammet, H.F., 1988. Fair-weather electricity on ground level. In: Proceedings of the Eighth International Conference on Atmospheric Electricity, Uppsala, Sweden, pp. 21-30.

Wilkening, M., 1990. Radon in the Environment. Elsevier Science Publishers, Amsterdam, The Netherlands, pp. 1-137.

Wilkening, M.H., 1985. Characteristics of atmospheric ions in contrasting environments. J. Geophys. Res. 90, 5933-5935.

Yu, F., Turco, R.P., 2001. From molecular clusters to nanoparticles: the role of ambient ionization in tropospheric aerosol formation. J. Geophys. Res. 106, 4797-4814. 